\title{
Evaluation with in vivo optical coherence tomography and histology of the vascular effects of the everolimus- eluting bioresorbable vascular scaffold at two years following implantation in a healthy porcine coronary artery model: implications of pilot results for future pre-clinical studies
}

\author{
Bill D. Gogas • Maria Radu • Yoshinobu Onuma • Laura Perkins • \\ Jennifer C. Powers • Josep Gomez-Lara • Vasim Farooq • Hector M. Garcia-Garcia • \\ Roberto Diletti $\cdot$ Richard Rapoza $\cdot$ Renu Virmani $\cdot$ Patrick W. Serruys
}

Received: 16 December 2010/ Accepted: 29 March 2011/Published online: 19 April 2011

(C) The Author(s) 2011. This article is published with open access at Springerlink.com

\begin{abstract}
To quantify with in vivo OCT and histology, the device/vessel interaction after implantation of the bioresorbable vascular scaffold (BVS). We evaluated the area and thickness of the strut voids previously occupied by the polymeric struts, and the neointimal hyperplasia (NIH) area covering the endoluminal surface of the strut voids $\left(\mathrm{NIH}_{\mathrm{EV}}\right)$, as well as the NIH area occupying the space between the strut voids $\left(\mathrm{NIH}_{\mathrm{BV}}\right)$, in healthy porcine coronary arteries at 2, 3 and 4 years after implantation of the device. Twenty-two polymeric BVS were implanted in the coronary arteries of 11 healthy Yucatan minipigs that
\end{abstract}

Bill D. Gogas and Maria Radu contributed equally to this manuscript.

B. D. Gogas · M. Radu · Y. Onuma · J. Gomez-Lara ·

V. Farooq · H. M. Garcia-Garcia · R. Diletti ·

P. W. Serruys $(\bowtie)$

Thoraxcenter, Erasmus University Medical Centre, 's Gravendijkwaal 230, 3015 Rotterdam, The Netherlands e-mail: p.w.j.c.serruys@erasmusmc.nl

L. Perkins · J. C. Powers · R. Rapoza

Abbott Vascular, Santa Clara, CA, USA

R. Virmani

CVPath, Gaithersburg, MA, USA underwent OCT at 2, 3 and 4 years after implantation, immediately followed by euthanasia. The areas and thicknesses of 60 corresponding strut voids previously occupied by the polymeric struts and the size of 60 corresponding $\mathrm{NIH}_{\mathrm{EV}}$ and $49 \mathrm{NIH}_{\mathrm{BV}}$ were evaluated with both OCT and histology by 2 independent observers, using a single quantitative analysis software for both techniques. At 3 and 4 years after implantation, the strut voids were no longer detectable by OCT or histology due to complete polymer resorption. However, analysis performed at 2 years still provided clear delineation of these structures, by both techniques. The median [ranges] areas of these strut voids were 0.04 [0.03-0.16] and 0.02 [0.01-0.07] $\mathrm{mm}^{2}$ by histology and OCT, respectively. The mean $( \pm \mathrm{SD})$ thickness by histology and OCT was $220 \pm 40$ and $120 \pm 20 \mu \mathrm{m}$, respectively. The median [ranges] $\mathrm{NIH}_{\mathrm{EV}}$ by histology and OCT was 0.07 [0.04-0.20] and $0.03[0.01-0.08] \mathrm{mm}^{2}$, while the mean $( \pm \mathrm{SD})$ $\mathrm{NIH}_{\mathrm{BV}}$ by histology and OCT was $0.13 \pm 0.07$ and $0.10 \pm 0.06 \mathrm{~mm}^{2}$. Our study indicates that in vivo OCT of the BVS provides correlated measurements of the same order of magnitude as histomorphometry, and is reproducible for the evaluation of certain vascular and device-related characteristics. However, histology systematically gives larger values for all the measured structures compared to OCT, at 2 years post implantation. 
Keywords Bioresorbable vascular scaffold .

Vascular healing - Optical coherence tomography . Histology

\section{Introduction}

Bioresorbable coronary scaffolds are a novel approach to the percutaneous treatment of coronary artery disease. Recently, the everolimus-eluting bioresorbable vascular scaffold (BVS) (Abbott Vascular, Santa Clara, Santa Clara, USA) has been studied in the first-in-man ABSORB cohort A trial, which demonstrated the feasibility and safety of this device, with a rate of major adverse cardiac events of $3.4 \%$ up to 3 years [1-3]. The BVS is composed of a backbone of poly-L-lactide (PLLA), covered with the polymer poly-D, L-lactide (PDLLA), containing and controlling the release of the drug, everolimus (Novartis, Basel, Switzerland). PLLA and PDLLA degrade to lactic acid which is metabolized via the Krebs' cycle during the bioresorption process. The radiolucent device is visualized on angiography by radio-opaque platinum markers located at each end [4]. The introduction of these new devices prompts us to refine our methods of evaluation, using state-ofthe-art imaging modalities, such as optical coherence tomography (OCT). This imaging technique has a near-histological resolution $(\sim 15 \mu \mathrm{m})$, which makes it ideal for studying the device/vessel interaction in detail [5]. As the polymeric struts are translucent, light-based imaging modalities are particularly suitable for this purpose. Up to now, histological morphometry has been crucial in the evaluation of the performance of new devices [6]. As histology is limited to animal and human post-mortem studies, in vivo assessment using OCT is highly desirable. This porcine study was set up in 2006 with the goal to evaluate the device/vessel interaction after implantation of the BVS at 2, 3 and 4 years, using OCT and histology. The qualitative strut-related characteristics with regards to the process of biodegradation were published recently [7]. In this part of the study, we sought to evaluate whether mimicking the histological morphometric approach using OCT is feasible and reproducible for the evaluation of the vascular healing following implantation with the BVS.

Specifically, we sought to compare a number of quantitative parameters assessed by ex vivo/"post processed" histology and in vivo/"non-processed" OCT, in order to assess the agreement between these techniques. These parameters include: the number and size of the structures resembling struts, and quantification of the tissue growth covering the endoluminal surface and the tissue growth between these structures.

\section{Methods}

Study sample and OCT imaging

Twenty two polymeric devices, BVS revision 1.0 $(3 \times 12 \mathrm{~mm})$ were implanted in 11 healthy Yucatan minipig coronary arteries, with a balloon: artery ratio of 1.2:1. The BVS revision 1.0 has three main components: the polymeric backbone, the polymeric drug reservoir, and the antiproliferative drug, everolimus. The polymeric scaffold is balloon-expandable, and is composed of a high molecular weight PLLA with serpentine rings interconnected by links. The scaffold body design is coated with a matrix of PDLLA and everolimus in a 1:1 ratio. The device is laser cut from an extruded tube and has two radioopaque platinum markers at both ends [8]. Since OCT at 3 and 4 years following implantation displayed no signal at the site where struts were expected to have been previously implanted, we evaluated only the devices available at 2 years follow-up. At this time point, the PLLA backbone is almost completely resorbed, as evidenced by gel permeation chromatography, and histology shows accumulations of proteoglycans (stained positively with Alcian blue) at corresponding sites. By OCT, however, these "strut voids" appear as well delineated hyporeflective foci. Since it is known that by OCT, immediately after implantation, BVS polymeric struts appear as black boxes with bright borders [1], these findings indicate that OCT does not distinguish between the BVS strut polymeric material and the provisional matrix that replaces the strut after full bioresorption [7]. Throughout the entire length of this manuscript, we will use the term "strut void" to describe these strut-like structures, previously occupied by the polymeric material.

OCT was performed in vivo using the M2 CV imaging system (LightLab Imaging, Westford, MA, USA). In brief, the low-pressure Helios ${ }^{\mathrm{TM}}$ occlusion 
balloon catheter was advanced distally to the region of interest over a conventional 0.014 inch angioplasty wire, which was then exchanged with the OCT ImageWire $^{\mathrm{TM}}$. After calibration of the image wire by correction of the Z-offset [9], the occlusion balloon catheter was withdrawn proximally to the region of interest, and inflated to 0.5-0.7 atmospheres. During image acquisition, blood clearance was achieved by manual continuous flushing with lactated Ringer's solution. Cross-sectional images were acquired at 15.6 frames/s, with an automatic pullback speed of $1 \mathrm{~mm} / \mathrm{s}$. Images were stored digitally for off-line analysis.

Processing for histology and selection of corresponding OCT and histology images

Animal sacrifice was performed immediately after OCT imaging by intravenous sodium pentobarbital infusion. The heart was explanted from the thoracic cavity, the aorta clamped, and the coronary arteries were pressure perfused at $100-120 \mathrm{~mm} \mathrm{Hg}$ : first with $0.9 \%$ saline, followed by $10 \%$ neutral buffered formalin for approximately $30 \mathrm{~min}$. Hearts were then immersed in formalin for complete fixation. Following this, arteries were carefully dissected off the heart. The location of the scaffolds was confirmed by high-contrast film-based radiographs (Faxitron X-ray Corp., Lincolnshire, IL, USA) and the specimens were dehydrated in a graded series of ethanol. The scaffolded segments were then embedded in methyl methacrylate (MMA) for polymerization [4]. The MMA block was sawed into three $4 \mathrm{~mm}$ segments, and three cross-sections were cut using a rotary microtome with a tungsten carbide blade: one at the proximal scaffold segment, $2 \mathrm{~mm}$ distal to the proximal metallic marker; one at the middle segment, $6 \mathrm{~mm}$ distal to the proximal marker; and one at the distal scaffold segment, $2 \mathrm{~mm}$ proximal to the distal marker. Finally, the samples were mounted and stained with hematoxylin and eosin (HE) and/or elastic Van Gieson (EVG).

Corresponding OCT cross-sections were selected by one observer (YO), using the distances from the platinum markers and anatomical landmarks, such as side branches, as references. Two observers (BG, MR) identified the corresponding structures of interest. The quantitative analysis was performed with the observers blinded to each other's results, as well as to the correspondence between the OCT and histology images. We assumed that the sharp boundary of the strut voids by histology corresponded to the sharply delineated bright borders of the "black boxes" by OCT.

Quantitative analysis of OCT and histology images

OCT and histology images were analyzed with the QCU-CMS software version 4.64 (Laboratory of Clinical and Experimental Image processing, Leiden, The Netherlands), which has previously been shown to provide correlated quantitative measurements as compared to the LightLab software [20]. Once images were uploaded, calibration was performed: for OCT, the diameter $(0.36 \mathrm{~mm})$ of the image wire was used, whilst histology images were calibrated using the scale bar provided by the pathologist. After calibration of the images, the following parameters were quantified: (1) the number of strut voids previously occupied by the polymeric struts (2) the lumen area and the area encompassing the abluminal surfaces of these strut voids; (3) the area and thickness of these strut voids and (4) the neointimal hyperplasia (NIH) area covering the endoluminal surface $\left(\mathrm{NIH}_{\mathrm{EV}}\right)$ and the NIH area between the strut voids $\left(\mathrm{NIH}_{\mathrm{BV}}\right)$ (Fig. 1). To be more specific, the measurements were performed in the following way (Figs. 1 and 2): 1 . "Scaffold" area: after manual localization of the strut voids by setting a green circle at the mid point of their abluminal surfaces, these points were connected automatically by a trace line placed by the software. In addition, the center of gravity of the scaffold area was determined automatically by the software. 2 . Lumen area: the lumen contour was automatically traced by the software; 3 . The area of the strut void: this was manually demarcated by following the contour of these structures; 4 . $\mathrm{NIH}_{\mathrm{BV}}$ : in order to demarcate the NIH areas laterally, we used the angle tool of the software, which takes the center of gravity of the scaffold as reference.

The rays of the angle tool were placed as help lines, at the edges of every strut void creating an area between these which was limited axially by the scaffold line and the lumen contour and laterally by the help lines (Fig. 1 and 2); 5. $\mathrm{NIH}_{\mathrm{EV}}$ : was defined as the area limited by the "help lines" placed at the edges of the strut voids, their endoluminal surfaces, 


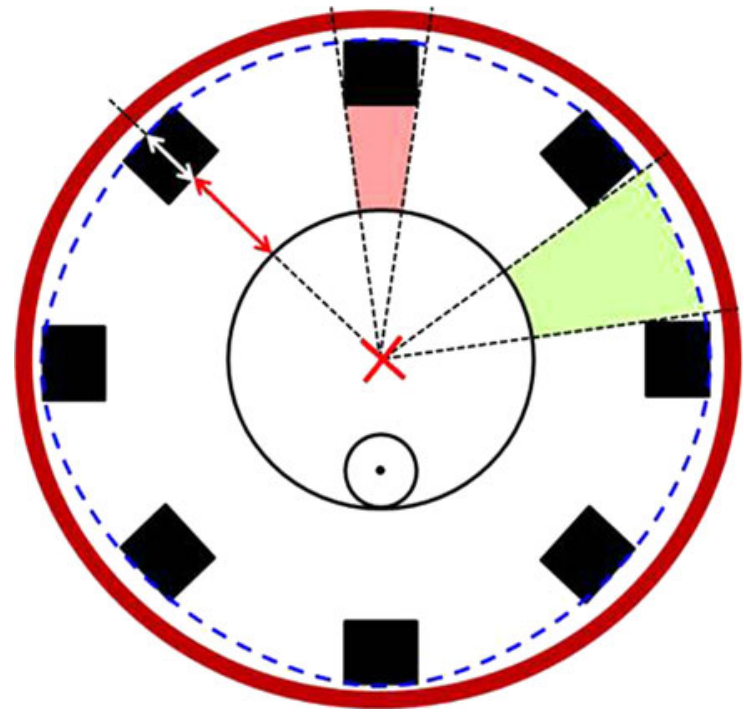

Fig. 1 Schematic representation of the quantitative analysis. Panel a The thick red line represents the vessel wall; the black continuous line, the lumen contour; black squares strut voids previously occupied by the polymeric struts; and the blue dotted line the abluminal "scaffold" area. The red cross indicates the center of gravity of the remnants of the scaffold, which was provided automatically by the software after manual indication of the mid point of the abluminal surfaces of the strut-like structures. The center of gravity point was used to place "the help lines" (black dotted lines) for the measurement of the neointimal hyperplasia area covering the endoluminal surface of these structures (red area), and the neointimal hyperplasia area between these structures (green area). The neointimal thickness (red arrow) was measured from the endoluminal surface of the strut voids to the lumen contour, along a line projected through the center of gravity of the scaffold and the mid point of the abluminal surface of these structures. The strut void thickness (white arrow) was measured in a similar way

and the lumen area contour; 6. Neointimal thickness: this was measured from the mid point of the endoluminal surface of the strut voids to the lumen contour, along a line projected through the center of gravity of the scaffold; 7: Strut void thickness: this was assessed by measuring the distance between the mid points of the endoluminal and abluminal surfaces of the strut voids.

\section{Statistical analysis}

Statistical analyses were performed with SPSS, version 16 (SPSS Inc.,Chicago, IL, USA). Discrete variables are presented as counts and percentages, and continuous variables as mean \pm standard deviations, or medians and interquartile ranges or ranges (minimum-maximum). The Pearson's correlation coefficient $\left(\mathrm{r}^{2}\right)$ was computed to compare OCT and histological measurements. Bland-Altman plots, displaying the systematic (mean absolute difference) and random (95\% limits of agreement) errors, and the interclass correlation coefficient for absolute agreement (ICCa) and consistency (ICCc) were used to assess the agreement between techniques. Interobserver variability was assessed using the correlation coefficient $\left(\mathrm{r}^{2}\right)$. A two-sided $\mathrm{p}$-value $\leq 0.05$ was considered significant.

\section{Results}

A total of six corresponding cross-sections were available for the purpose of this study (Fig. 3). Histology displayed 75 strut voids previously occupied by the polymeric struts whilst OCT showed only 60 . Fifteen of these strut voids by histology could not be identified in the OCT images due to non-uniform rotational distortion, marginalization of the image wire into a side branch and a long distance to the image wire, together with a low light incidence angle resulting in a high light attenuation (Fig. 4). Thus, a total of 60 corresponding strut voids were included in the analysis. In only 1 of 6 frames were all corresponding strut remnants visualised by both OCT and histology with the consequence that the lumen and scaffold area was only accurately assessed in this frame (OCT: 2.78 and $5.14 \mathrm{~mm}^{2}$; histology: 1.02 and $4.40 \mathrm{~mm}^{2}$, for lumen and scaffold area, respectively). The ratio between the lumen area and stent area for the OCT was 0.54 while for histology was 0.23 and the $\%$ area obstruction of the scaffold for OCT was $45 \%$ while for histology $76 \%$. Apart from the strut voids that were not adequately visualized, all images were successfully analysed using the histomorphometrical methodology with the dedicated off-line software. Table 1 and Fig. 5 show the descriptive statistics and Bland-Altman plots for the different parameters measured with OCT and histology. The average difference and $95 \%$ limits of agreement were: for the strut area: 0.03 [0.07; $-0.01]$, for the strut thickness: 0.10 [0.18; 0.02], for the NIHEV: $0.04[0.10 ;-0.02]$ and for the NIHBV: $0.03[0.21 ; 0.15]$. In general, histomorphometry provided larger values for all parameters compared 

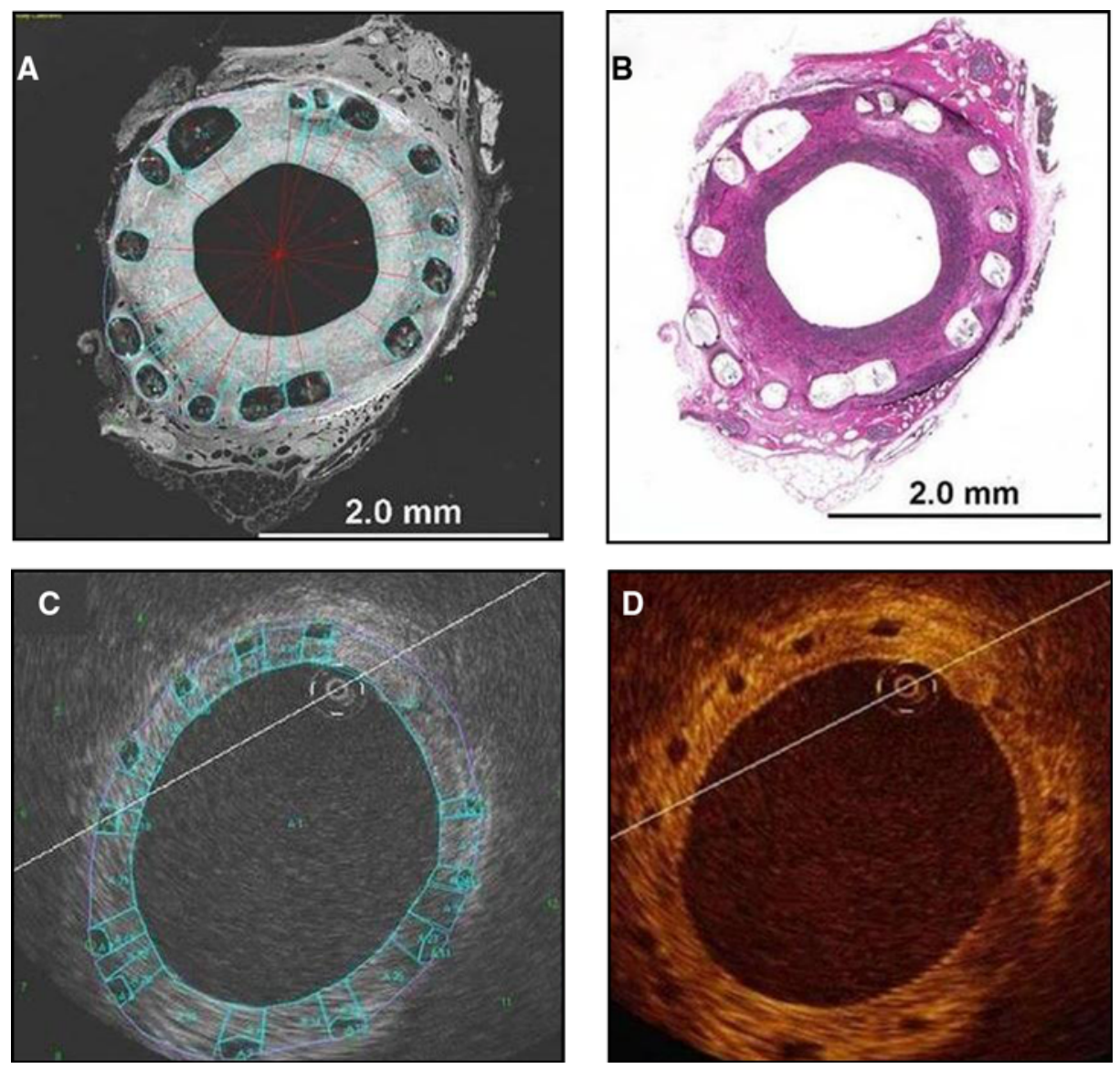

Fig. 2 Demonstration of quantitative measurements by histology and OCT. Panels A and $\mathbf{B}$ show the inverted grey scale and color histology images, respectively, with superimposed quantitative measurements (green lines in $\mathbf{A}$ ), and panels $\mathbf{C}$ and $\mathbf{D}$, the corresponding grey scale and sepia OCT, with the

to OCT. Interobserver variability was evaluated for all variables assessed with histology and OCT (Fig. 6). The mean (SD) differences between observers were negligible for the parameters measured in the histological sections (area and thickness of strut voids $0.00(0.00) \mathrm{mm}^{2}$ and $0(30) \mu \mathrm{m}$, repcetively; $\mathrm{NIH}_{\mathrm{EV}} 0.00(0.00) \mathrm{mm}^{2}$, and $\mathrm{NIH}$ BV $0.00(0.01)$ $\mathrm{mm}^{2}$ ), as well as for those assessed in the OCT crosssections (for area and thickness of strut voids: 0.00 (0.00) $\mathrm{mm}^{2}$ and 0 [10] $\mu \mathrm{m}$, respectively; for $\mathrm{NIH}_{\mathrm{EV}}$ $0.00(0.01) \mathrm{mm}^{2}$, and $\left.\mathrm{NIH}_{\mathrm{BV}}-0.03(0.01) \mathrm{mm}^{2}\right)$.

The Lin's correlation coefficient interpreted by the ICCc and ICCa for the area of strut voids were: 0.34 [95\% confidence interval (CI): $0.10-0.55], P<0.004$ and 0.18 [95\% CI: -0.08 to 0.43$], P<0.004$; for the thickness of these structures: 0.08 [95\% CI: -0.18 to respective measurements (only $\mathbf{C}$ ). The red lines are provided by the software, and are projected from the center of gravity of the scaffold through the mid points of the abluminal surfaces of the struts

0.33], $P=0.271$ and 0.01 [95\% CI: -0.03 to 0.07 ], $P=0.271$; for $\mathrm{NIH}_{\mathrm{EV}}: 0.39$ [95\% CI: $0.15-0.59$ ], $P<0.001$ and 0.19 [95\% CI: -0.09 to 0.46 ], $P<$ 0.001 ; and for $\mathrm{NIH}_{\mathrm{BS}}$ : -0.03 [95\% CI: -0.29 to 0.29 ], $P=0.50$ and -0.03 [95\% CI: -0.27 to 0.28 ], $P=0.50$.

The Pearson's correlation coefficient $\left(\mathrm{r}^{2}\right)$ for the interobserver variability for the histology assessment was: for the thickness and area of the strut voids thickness: $r^{2}=0.89$ and $r^{2}=0.78$, respectively; for $\mathrm{NIH}_{\mathrm{EV}}: \mathrm{r}^{2}=0.87$; and for $\mathrm{NIH}_{\mathrm{BV}}: \mathrm{r}^{2}=0.86(P<$ 0.001 for all analyses). Corresponding results for the OCT measurements were: for thickness and area of strut voids: $\mathrm{r}^{2}=0.70$ and $\mathrm{r}^{2}=0.57$, respectively; for $\mathrm{NIH}_{\mathrm{EV}}: \mathrm{r}^{2}=0.67$; and for $\mathrm{NIH}_{\mathrm{BV}}: \mathrm{r}^{2}=0.66(P<$ 0.001 for all analyses). 

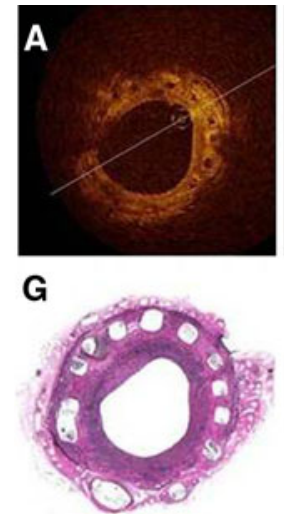

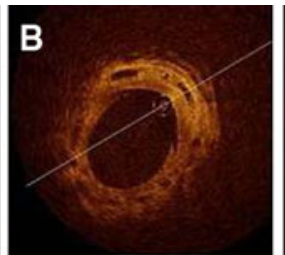

H

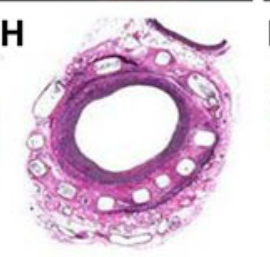

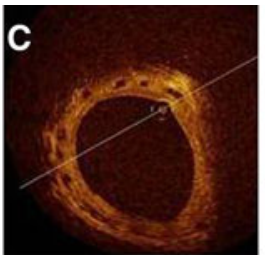

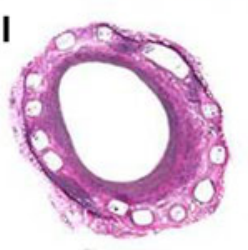

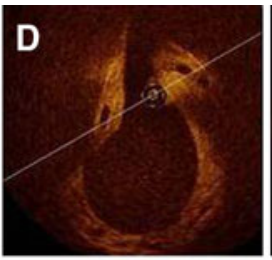

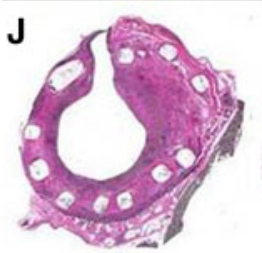

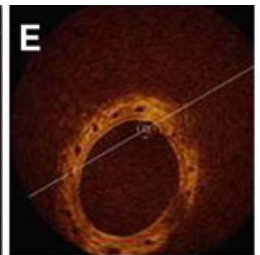
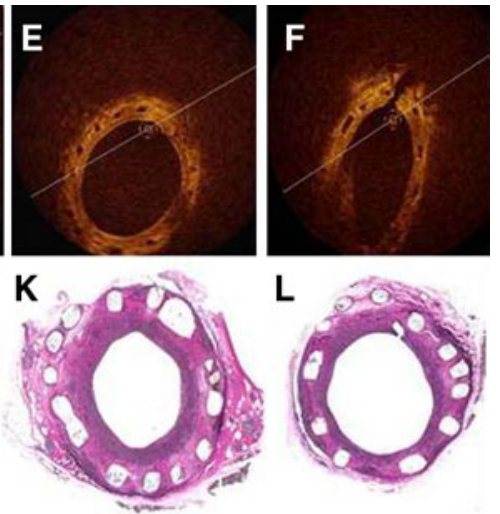

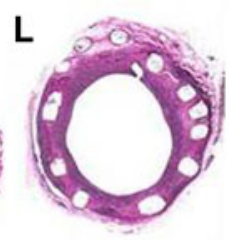

Fig. 3 Cross-sections of corresponding OCT and histology of the left anterior descending artery $(A / G, B / H, C / I)$, and the right coronary artery $(D / J, E / K, F / L)$. Histology specimens are stained with elastic Van Gieson
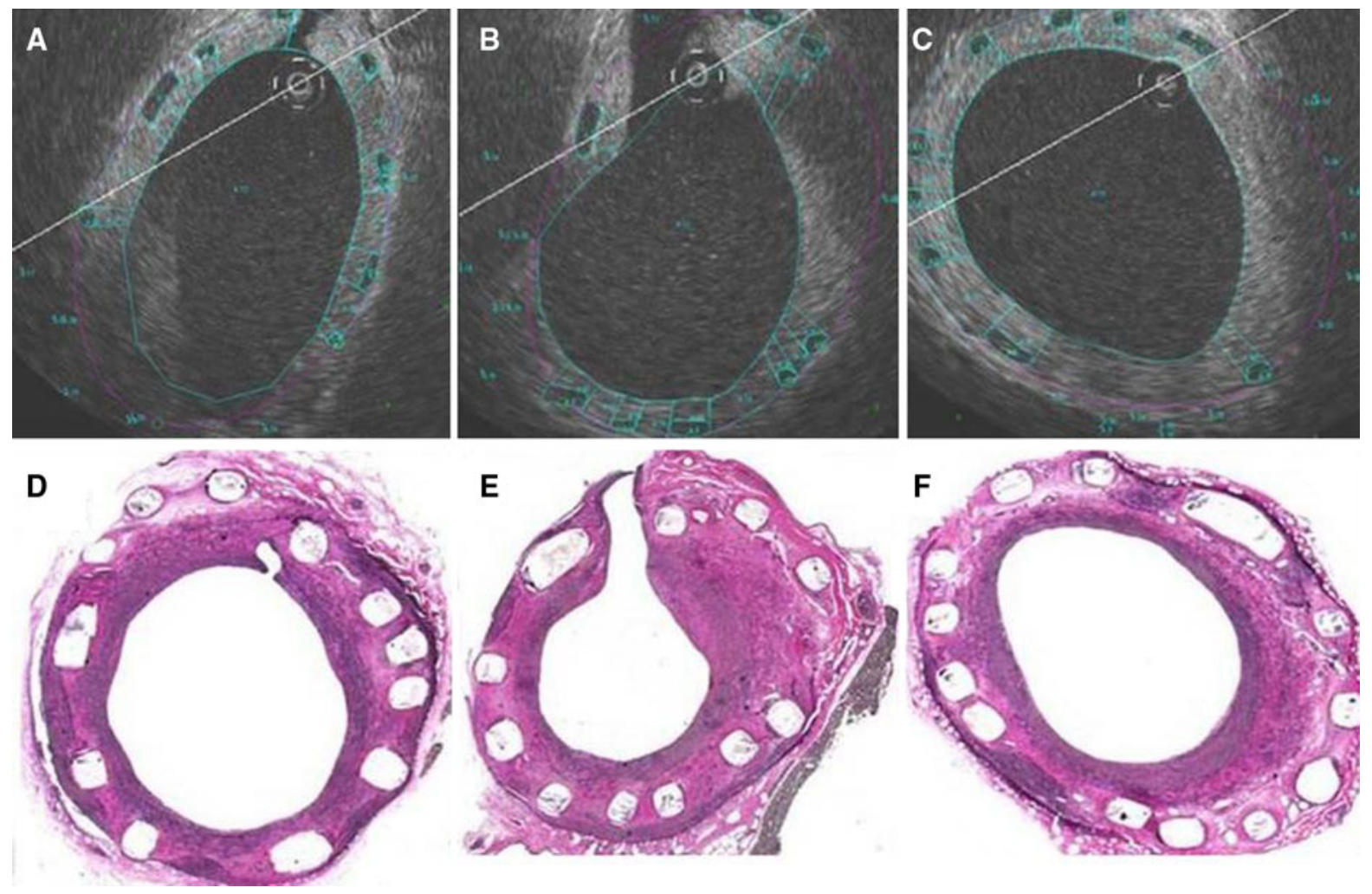

Fig. 4 Factors precluding identification of some of the strut voids in corresponding OCT and histology images. Panels AC demonstrate how non-uniform rotational distortion (A), marginalisation of the image wire into a side branch $(\mathbf{B})$, and a long distance between the image wire and black boxes preclude visualisation of these strut voids by OCT, as compared to corresponding histology (D-F). Due to the lack of visualization of these structures, abluminal scaffold areas could not be accurately assessed. In order to obtain reproducible measurements, it was before the analysis decided to trace the scaffold area only at the sites of black boxes that are visualized, with the consequence of an underestimation of the "true" OCT scaffold area 
Table 1 Descriptive statistics of all parameters measured by OCT and histology

\begin{tabular}{lll}
\hline & OCT & Histology \\
\hline $\begin{array}{l}\text { Area of the strut voids, } \\
\mathrm{mm}^{2}\end{array}$ & $0.02(0.01-0.07)$ & $0.04(0.03-0.16)$ \\
$\begin{array}{l}\text { Thickness of the strut } \\
\text { voids }\end{array}$ & $120(70-180)$ & $220(120-350)$ \\
$\mathrm{NIH}_{\mathrm{BV}}, \mathrm{mm}^{2}$ & $0.03(0.01-0.08)$ & $0.07(0.04-0.20)$ \\
$\mathrm{NIH}_{\mathrm{EV}}, \mathrm{mm}^{2}$ & $0.09(0.01-0.27)$ & $0.13(0.01-0.31)$
\end{tabular}

$N I H$ neointimal hyperplasia, $B V$ between the voids, $E V$ endoluminal surfaces of the voids, values are median (range)
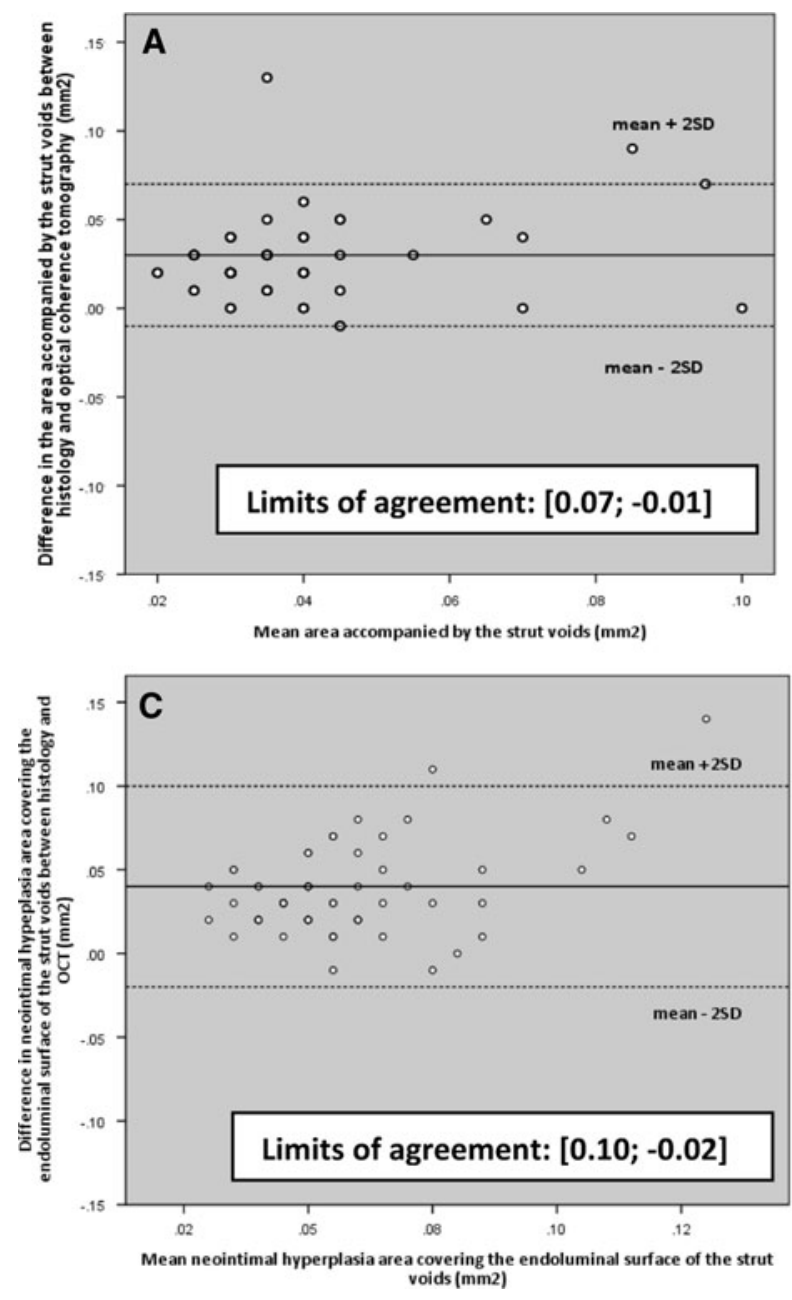

Fig. 5 Bland-Altman plots depicting the agreement between techniques for the evaluation of the area (panel A) and thickness (panel B) of the strut voids previously occupied by the polymeric struts, the neointimal hyperplasia area covering

\section{Discussion}

In the present study, we performed a quantitative analysis of in vivo OCT images of the remnants of bioresorbable vascular scaffolds at 2 years following implantation, using a methodology similar to the morphometric approach used with histology. The main findings of this pilot study are: 1. Histology appears to systematically give larger values, when compared with OCT; 2 . the approach similar to histomorphometry for quantitative analysis of OCT images is feasible and reproducible for the evaluation
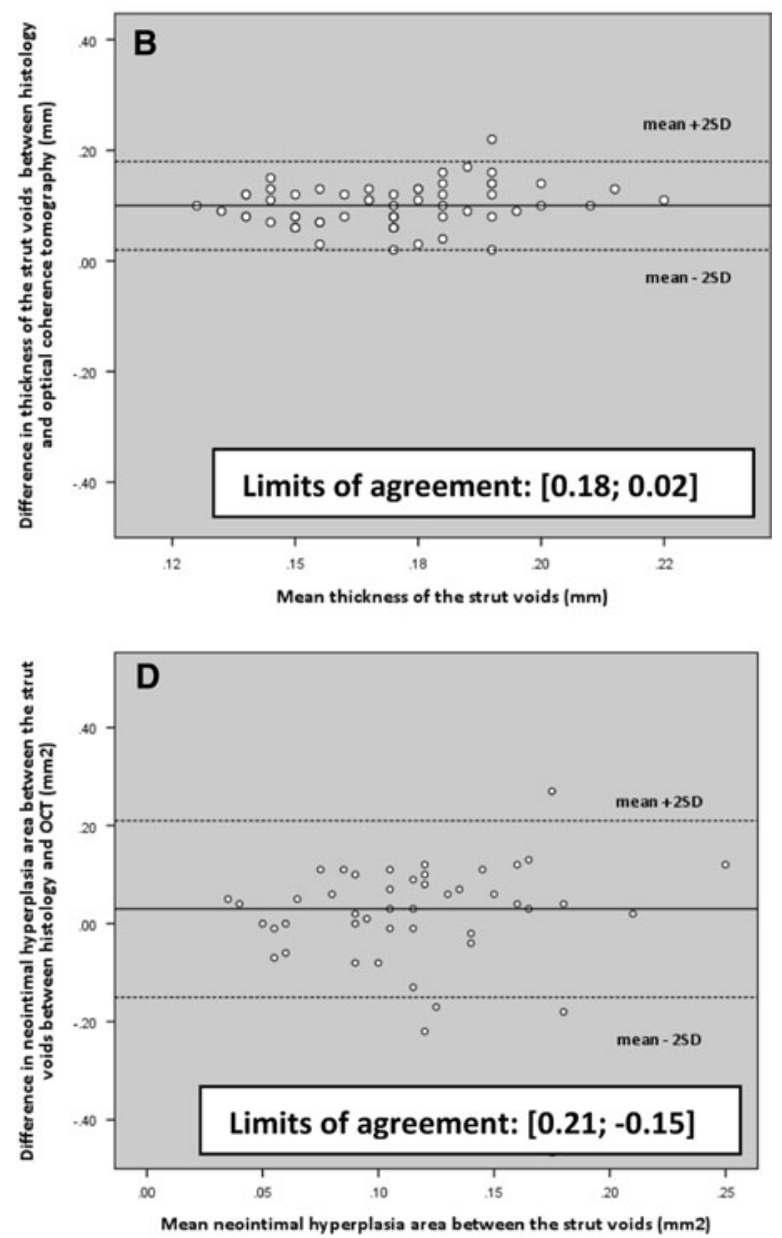

the endoluminal surface of these voids (panel $\mathbf{C}$ ), and the neointimal hyperplasia area between the voids (panel D), with histology and OCT 
at follow up after implantation of the BVS; and 3. despite the use of anatomical landmarks and intrascaffold radiopaque markers to identify corresponding cross-sections, higher numbers of strut voids were visualized by histology than by OCT.

Differences in quantitative measurements between OCT and histology

The observation that quantitative measurements by histology and OCT may differ is not new, as previous studies have suggested that histological processing may induce a certain degree of artifacts related to formalin fixation and dehydration [10]. Surprisingly however, our study showed that all morphological characteristics analyzed were systematically larger by histology as compared to OCT. More specifically, the strut void area, strut void thickness, $\mathrm{NIH}_{\mathrm{EV}}$ and $\mathrm{NIH}_{\mathrm{BV}}$ were $100 \%, 83 \%, 130 \%$ and $44 \%$ larger by histology compared to OCT, respectively. Several factors may have contributed to this difference. The first involves the calibration of the OCT image wire by adjustment of the Z-offset before image acquisition, as well as calibration of the scaling of OCT and histology images before analysis, which are crucial for any quantitative measurement. In the present study, these were all performed according to current standards [9]. Secondly, differences can potentially be related to the application of different analysis softwares for different techniques. We tried to circumvent this by utilizing the same software, as well as by using semi-automatic approaches, for all analyses, which was evidenced in the good interobserver reproducibility seen. Nevertheless, the quantitative results by histology were systematically larger than by OCT, as compared to previous studies, even if these applied different softwares for the different techniques [11, 12]. Other interfering factors are therefore likely to be involved. For the NIH areas, our results resemble those reported by Murata et al. and Templin et al., who found that histology estimated the NIH areas covering metallic stents slightly higher than OCT, at 28 and 90 days, and at 10, 14 and 28 days, respectively [13, 14]. However, in our study, the overestimation by histology was greater. This may be related to the combined differences in: the mechanical constraints imparted on the tissue between the bioresorbable vascular scaffold as compared to metallic stents; in the tissue composition at time point of examination (2 years), which includes a higher proportion of collagen and smooth muscle cells as compared to time points less than 90 days [15]; and in the composition of the strut voids which, as shown by Onuma et al., are replaced by highly water-containing acid mucopolysacharides material, which stains positively with Alcian Blue, at this time point [7]. Further, previous studies have indicated that formaldehyde, which we used for tissue fixation, can cause dimensional changes that are dependent on the composition of the tissue (for example causing swelling in liver tissue and shrinkage in muscle tissue), the $\mathrm{pH}$ of the tissue, and the temperature and concentration of the fixative [10]. In addition to tissue fixation, dehydration with ethanol, embedding and polymerization in MMA, and subsequent deplastization likely further impacted the tissue dimensions obtained histologically. Considering the contrasting nature of the tissues at late followup of the BVS, namely the proteoglycan-rich tissue replacing pre-existing struts compared to the surrounding smooth muscle cell and collagen-dense tissue of the arterial wall, these tissue-specific dimensional changes are especially notable at follow-up after implantation of the BVS. This is supported by the qualitative results regarding the histological appearance of the strut-like structures at 2 and 3 years. At 2 years, the strut voids appear more spherical, having a highly water-containing proteoglycan, while they are contracted and almost completely coalesced into the arterial wall at 3 years (Fig. 6) [7]. Considering this, it is likely that the proteoglycan-based nature of strut foci at 2 years resulted in their swelling as an artifact of histological processing.

The fact that OCT was performed in vivo, when the vessel has a tonus and is naturally pressurized, may also explain some of the discrepancies, although efforts were made to pressurize vessels during histology preparation. However, the most plausible explanation involves the attempt to correspond OCT and histology cross-sections, which depends on the orientation of the OCT image wire relative to the vessel curvature and relative to the location in the vessel lumen, which in turn influence how the OCT "biotome" cross-sects the tissue and the scaffold. The difficulty finding completely corresponding cross-sections may be further affected by the 

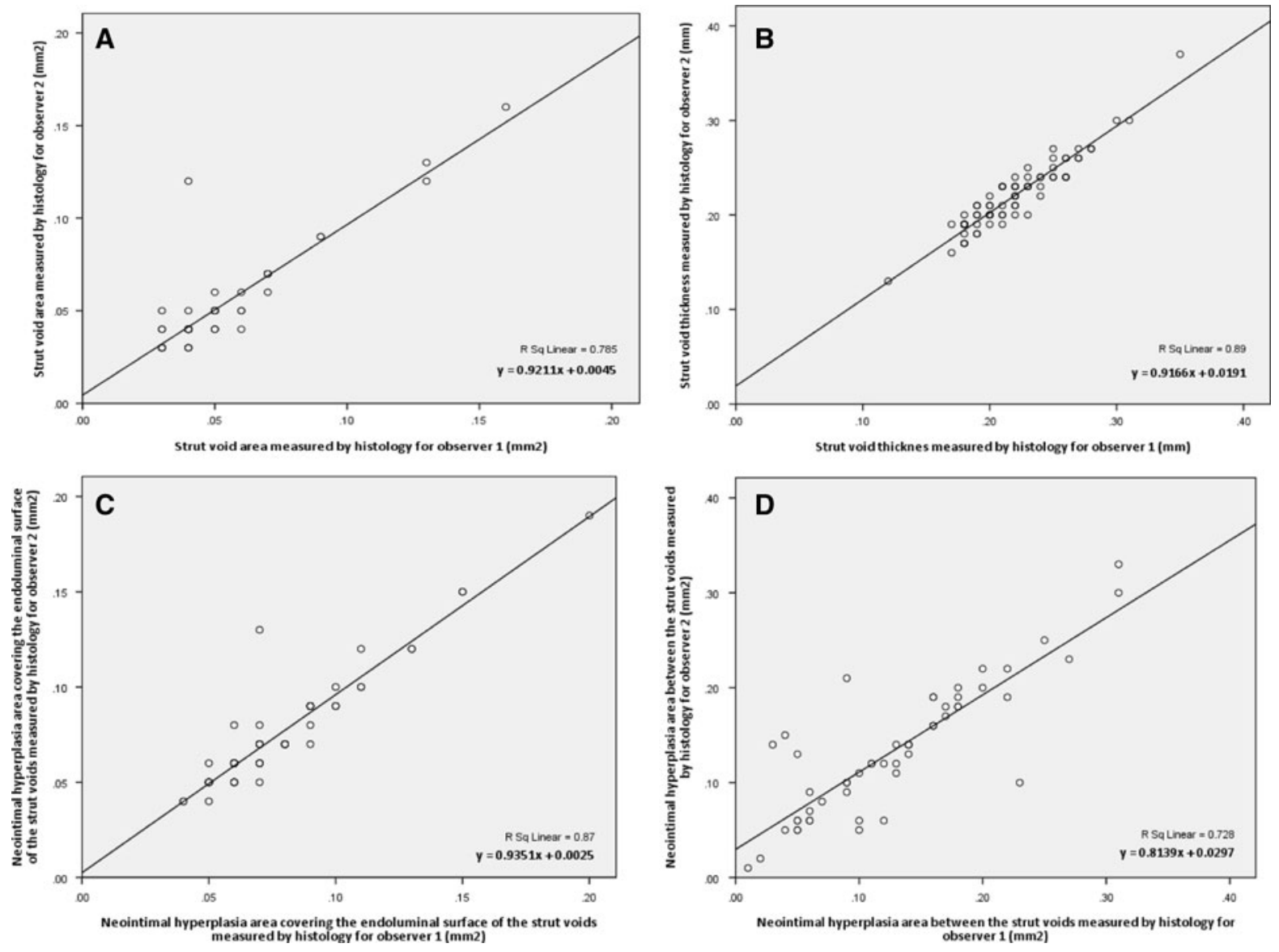

Fig. 6 Linear regression analysis plots depicting the interobserver variability for the evaluation of the area and thickness of the strut voids, the neointimal hyperplasia area covering the

differences in slice thicknesses of the samples provided by the different techniques. For histology, the minimum slice thickness possible to obtain, is in the range of $4-5 \mu \mathrm{m}$ with a sampling interval of $100 \mu \mathrm{m}[16]$, and depends on the microtome, while the minimum frame thickness available with the OCT system used in the present study is $60 \mu \mathrm{m}$ and depends on the longitudinal sampling distance, which is in turn related to the frame rate (15.6 frames/s) and the pullback speed $(1 \mathrm{~mm} / \mathrm{s})$. Nevertheless, it should be stressed that wherever possible, efforts were made to secure corresponding cross-sections by histology and OCT using the scaffold platinum markers and anatomical structures, as landmarks. Thus, our report highlights some of the difficulties that may be encountered in this type of study, which are important to acknowledge (Fig. 7).

endoluminal surface of these voids, and the neointimal hyperplasia area between the voids, with histology (panels A-D) and OCT (panels E-H), respectively

Consideration of technical aspects with OCT imaging

Although efforts were made to obtain matched crosssections between OCT and histology using landmarks, we found a higher density of strut voids by histology than by OCT. In addition to the factors mentioned above, we noticed that the intrinsic properties of the OCT technology related to the use of light also influenced our analysis. By marginalization of the light source, causing an acute incidence angle of the light on the vessel wall, as well as by the relatively low scan diameter of the employed time domain-OCT system $(7 \mathrm{~mm})$ compared to newer generation frequency domain (FD)-OCT systems $(10 \mathrm{~mm})$, visualisation of the strut voids along the entire 360 degree vessel circumference was hindered 

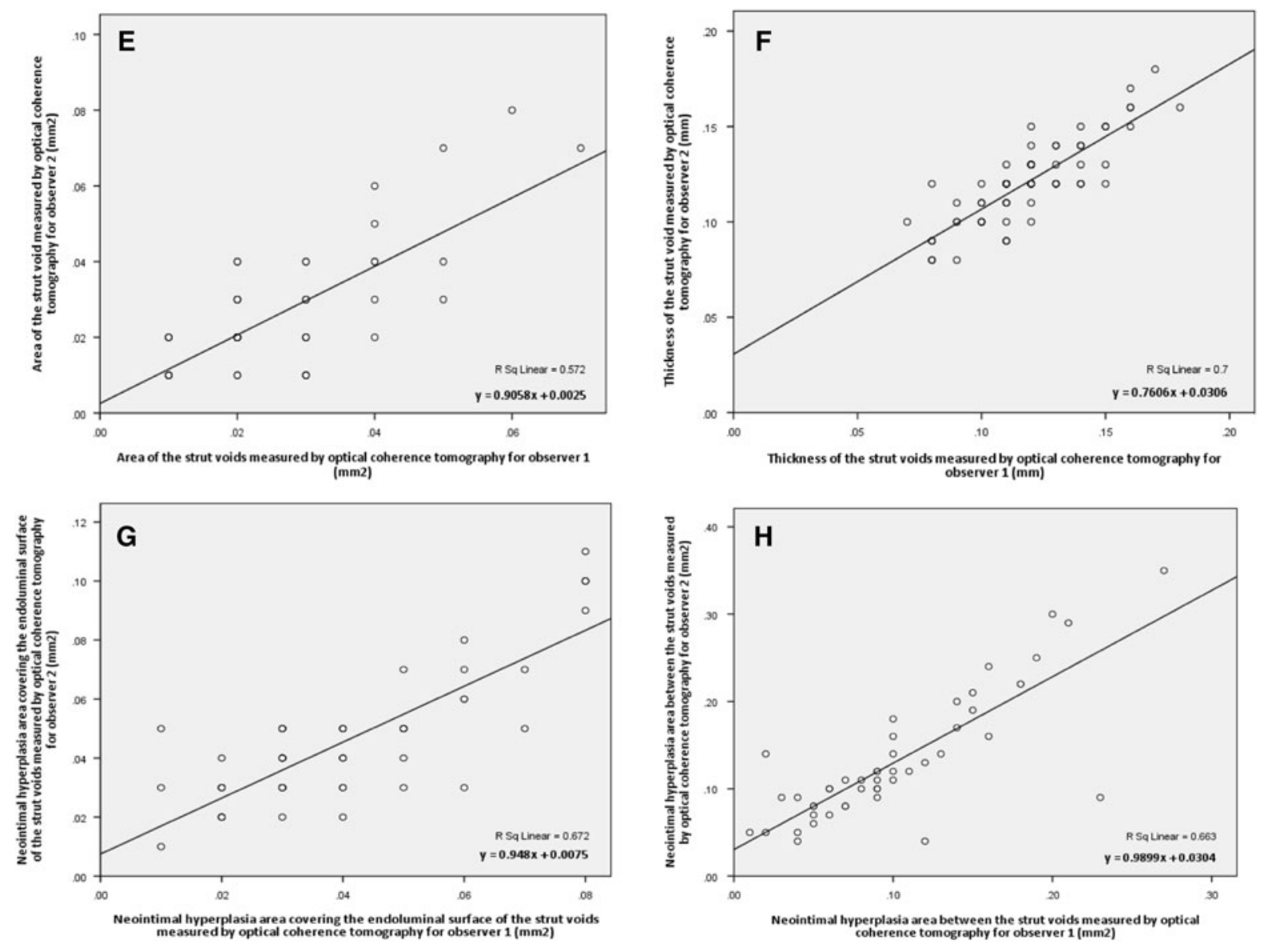

Fig. 6 continued

(Fig. 3B, C), which prevented the identification of these structures and the accurate delineation of the abluminal scaffold area, as well as delineation of the lumen area. Nevertheless, the only available accurate corresponding lumen and scaffold areas by OCT and histomorphometry showed that measurements by OCT were larger than those by histology, which is in line with previous studies [11-13]. Despite the potential advantages of in vivo "non-processed" OCT, the presence of non-uniform rotational distortion, which is related to vessel tortuosity, as well as the presence of artefacts due to heart motion in systole and diastole, further complicated the selection of perfectly corresponding frames. The new generation FD-OCT which has a much higher frame rate, allowing a higher pullback-speed without significant loss in longitudinal sampling density [14, 17 , 18], promises to overcome some of these issues, together with recent advances allowing retrospective reconstruction of gated OCT acquisitions [19]. However, these technologies were not available at the time of data acquisition.

\section{Histomorphometry-like analysis with OCT}

Onuma et al. recently described a qualitative analysis of OCT images of the polymeric struts of the BVS. As opposed to that analysis, our study focused on the evaluation of the quantitative tissue response around the strut voids previously occupied by the polymeric struts in terms of neointimal hyperplasia between and on the endoluminal surface of these, which we found to be feasible and reproducible, with a good interobserver reproducibility. Despite the mentioned issues regarding comparison between OCT and histology, OCT represents at present the in vivo imaging modality with the highest resolution, which enables 


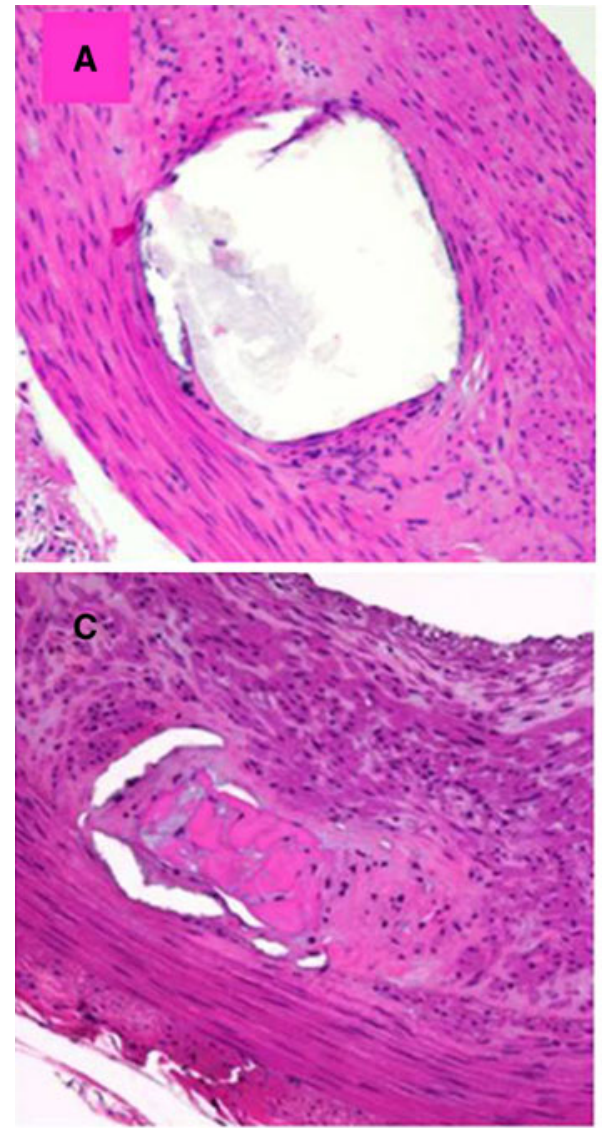

Fig. 7 Histological examples of the appearance of strut voids at 2 and 3 years following implantation of the bioresorbable vascular scaffold. Panels A-D show strut voids at 2 and 3 years follow-up, respectively. At 2 years, the proteoglycan-rich matrix appears to collapse in the middle of the void upon histological preparation, giving a spherical appearance, while

us to evaluate fine details in the assessment of the device/vessel interaction.

\section{Study limitations}

Our initial goal was to assess the morphometric parameters of the remnants of the device implanted with OCT at 2, 3, and 4 years following implantation. As part of the degradation process, the number of bioresorbable struts identified by OCT decreased with time. We now know that the polymeric struts are completely resorbed and replaced by proteoglycans by 2 years. However, this respective time point could not be foreseen at the time of planning of the study. For the comparison of different measurements

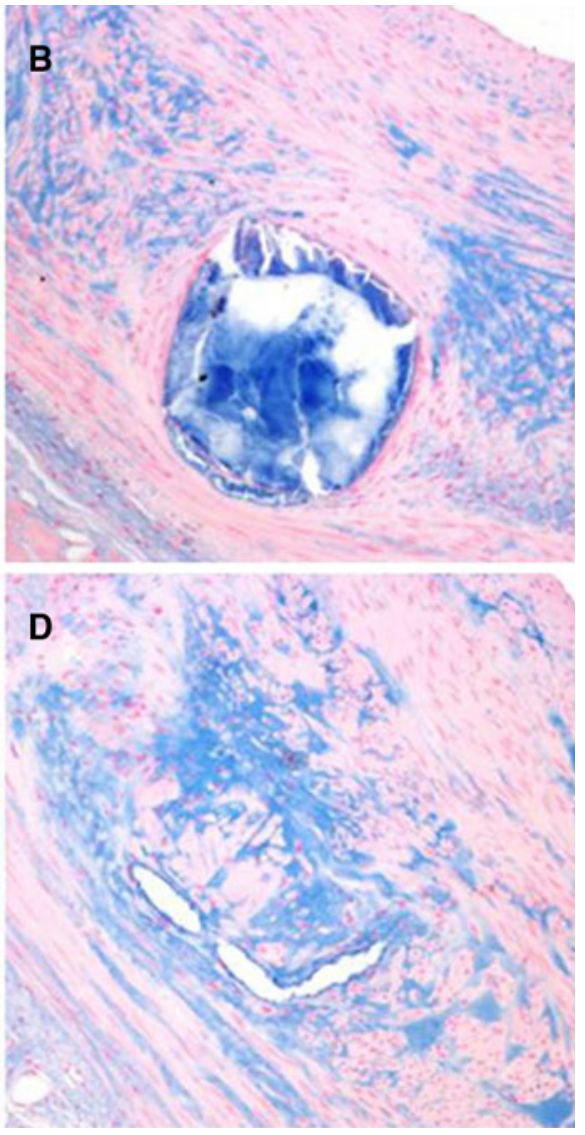

the matrix at 3 years is coalesced with the neointima of the vessel wall, giving the impression that the borders of the contents of the void are better held together with the neointima. Panels $\mathbf{A}$ and $\mathbf{C}$ are stained with hematoxylin and eosin, while panels $\mathbf{B}$ and $\mathbf{D}$ are stained with Alcian blue. Reproduced from Onuma et al. Circulation 2010

by OCT and histology, it was necessary to select a time point where strut-like structures (strut voids) are fully visible with OCT. Consequently, specimens at 3 and 4 years could not be included in this study, wherefore the sample size was relatively small. We cannot dismiss the possibility that the low sample size could, to some extent, explain the relatively large distribution of individual parameters. Nevertheless, we believe that the findings of this pilot study are interesting as they represent our initial quantitative experience with the novel bioresorbable technology, and may serve as a guide to the planning of future trials with corresponding OCT and histomorphometry to evaluate bioresorbable vascular scaffolds. 


\section{Conclusion}

The present pilot study showed that an approach for quantitative analysis of OCT images akin to histomorphometry is feasible and reproducible for the evaluation of the vascular healing at follow up after implantation of the BVS and that corresponding OCT and histomorphometry provide results of the same order of magnitude. Despite the use of landmarks to identify corresponding cross-sections, histology systematically provided larger measurements for all studied parameters. Whether this is related to factors influencing acquisition and processing of images, or the bioresorbable nature of the device, requires further investigation, for example using the newgeneration FD-OCT, and a larger sample analysed with a higher sampling density.

Acknowledgments Bill D. Gogas wishes to acknowledge the continued funding support of the Hellenic Heart Foundation (ELIKAR), Athens, Greece.

Conflicts of interest Laura Perkins, Jennifer Powers, and Richard Rapoza are employees of Abbott Vascular.

Open Access This article is distributed under the terms of the Creative Commons Attribution Noncommercial License which permits any noncommercial use, distribution, and reproduction in any medium, provided the original author(s) and source are credited.

\section{References}

1. Ormiston JA, Serruys PW, Regar E, Dudek D, Thuesen L, Webster MW, Onuma Y, Garcia-Garcia HM, McGreevy R, Veldhof S (2008) A bioabsorbable everolimus-eluting coronary stent system for patients with single de novo coronary artery lesions (ABSORB): a prospective openlabel trial. Lancet 371(9616):899-907

2. Serruys PW, Ormiston JA, Onuma Y, Regar E, Gonzalo N, Garcia-Garcia HM, Nieman K, Bruining N, Dorange C, Miquel-Hebert K, Veldhof S, Webster M, Thuesen L, Dudek D (2009) A bioabsorbable everolimus-eluting coronary stent system (ABSORB): 2-year outcomes and results from multiple imaging methods. Lancet 373(9667):897-910

3. Onuma Y, Serruys PW, Ormiston JA, Regar E, Webster M, Thuesen L, Dudek D, Veldhof S, Rapoza R (2010) Threeyear results of clinical follow-up after a bioresorbable everolimus-eluting scaffold in patients with de novo coronary artery disease: the ABSORB trial. Euro Interven 6(4):447453

4. Ormiston JA, Serruys PW (2009) Bioabsorbable coronary stents. Circ Cardiovasc Interv 2(3):255-260
5. Regar E, Schaar JA, Mont E, Virmani R, Serruys PW (2003) Optical coherence tomography. Cardiovasc Radiat Med 4(4):198-204

6. Virmani R, Kolodgie FD, Farb A, Lafont A (2003) Drug eluting stents: are human and animal studies comparable? Heart 89(2):133-138

7. Onuma Y, Serruys PW, Perkins LE, Okamura T, Gonzalo N, Garcia-Garcia HM, Regar E, Kamberi M, Powers JC, Rapoza R, van Beusekom H, van der Giessen W, Virmani $R$ (2010) Intracoronary optical coherence tomography and histology at 1 month and 2, 3, and 4 years after implantation of everolimus-eluting bioresorbable vascular scaffolds in a porcine coronary artery model. An attempt to decipher the human optical coherence tomography images in the ABSORB trial. Circulation 122(22):2288-2300

8. Okamura T, Garg S, Gutierrez-Chico JL, Shin ES, Onuma Y, Garcia-Garcia HM, Rapoza RJ, Sudhir K, Regar E, Serruys PW (2010) In vivo evaluation of stent strut distribution patterns in the bioabsorbable everolimus-eluting device: an OCT ad hoc analysis of the revision 1.0 and revision 1.1 stent design in the ABSORB clinical trial. Euro Interven 5(8):932-938

9. Gonzalo N, Garcia-Garcia HM, Serruys PW, Commissaris KH, Bezerra H, Gobbens P, Costa M, Regar E (2009) Reproducibility of quantitative optical coherence tomography for stent analysis. EuroIntervention 5(2):224-232

10. Bahr GF, Bloom G, Friberg U (1957) Volume changes of tissues in physiological fluids during fixation in osmium tetroxide or formaldehyde and during subsequent treatment. Exp Cell Res 12(2):342-355

11. Suzuki Y, Ikeno F, Koizumi T, Tio F, Yeung AC, Yock PG, Fitzgerald PJ, Fearon WF (2008) In vivo comparison between optical coherence tomography and intravascular ultrasound for detecting small degrees of in-stent neointima after stent implantation. JACC Cardiovasc Interv 1(2): 168-173

12. Gonzalo N, Serruys PW, Garcia-Garcia HM, van Soest G, Okamura T, Ligthart J, Knaapen M, Verheye S, Bruining N, Regar E (2009) Quantitative ex vivo and in vivo comparison of lumen dimensions measured by optical coherence tomography and intravascular ultrasound in human coronary arteries. Rev Esp Cardiol 62(6):615-624

13. Murata A, Wallace-Bradley D, Tellez A, Alviar C, Aboodi M, Sheehy A, Coleman L, Perkins L, Nakazawa G, Mintz G, Kaluza GL, Virmani R, Granada JF (2010) Accuracy of optical coherence tomography in the evaluation of neointimal coverage after stent implantation. JACC Cardiovasc Imaging 3(1):76-84

14. Templin C, Meyer M, Muller MF, Djonov V, Hlushchuk R, Dimova I, Flueckiger S, Kronen P, Sidler M, Klein K, Nicholls F, Ghadri JR, Weber K, Paunovic D, Corti R, Hoerstrup SP, Luscher TF, Landmesser U (2010) Coronary optical frequency domain imaging (OFDI) for in vivo evaluation of stent healing: comparison with light and electron microscopy. Eur Heart J 31(14):1792-1801

15. Farb A, Kolodgie FD, Hwang JY, Burke AP, Tefera K, Weber DK, Wight TN, Virmani R (2004) Extracellular matrix changes in stented human coronary arteries. Circulation 110(8):940-947

16. Bruining N, Knaapen M, de Winter S, Van Langenhove G, Serruys PW, Hamers R, de Feijter PJ, Verheye S (2009) A 
histological "fly-through" of a diseased coronary artery. Circ Cardiovasc Imaging 2(2):e8-e9

17. Kawase Y, Suzuki Y, Ikeno F, Yoneyama R, Hoshino K, Ly HQ, Lau GT, Hayase M, Yeung AC, Hajjar RJ, Jang IK (2007) Comparison of nonuniform rotational distortion between mechanical IVUS and OCT using a phantom model. Ultrasound Med Biol 33(1):67-73

18. Okamura T, Onuma Y, Garcia-Garcia H, Bruining N, Serruys $\mathrm{P}$ High-speed intracoronary optical frequency domain imaging: implications for three-dimensional reconstruction and quantitative analysis (submitted)

19. Sihan K, Botha C, Post F, De Winter S, Gonzalo N, Regar E, Serruys P, Hamers R, Bruining N (2010) Retrospective image-based gating of intracoronary optical coherence tomography: implications for quantitative analysis. EuroIntervention 6. [Epub ahead of print]

20. Okamura T, Gonzalo N, Gutierrez-Chico JL, Serruys P, Bruining N, de Winter S, Dijkstra J, Commossaris K, van Geuns RJ, van Soest G, Ligthart J, Regar E (2010) Reproducibility of coronary Fourier domain optical coherence tomography: quantitative analysis of in vivo stented coronary arteries using three different software packages. EuroIntervention 6:371-379 